\title{
Imaginarios sociales y conflictos en las expresiones de la música vallenata y la champeta en el Caribe colombiano*
}

[Separata]

Marlys Cano Yepez ${ }^{* *}$

\author{
Recibido:4 de junio de 2020 \\ Aprobado: 13 de noviembre de 2020
}

Citar como:

Cano, M. (2021). Imaginarios sociales y conflictos en las expresiones de la música vallenata y champeta en el caribe colombiano. Análisis, 53(99).

https://doi.org/10.15332/21459169.6803

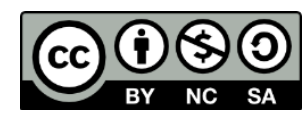

\section{Resumen}

Este artículo de reflexión, resultante de un proyecto de investigación estricta, permitió desde un horizonte sociológico un análisis del enfoque discursivo que enmarca el nacimiento y desarrollo de la champeta y el vallenato en las poblaciones donde estos son representativos (Las ciudades de Cartagena y Valledupar respectivamente). Además, permitió entender la relación existente entre las expresiones musicales de estos géneros, teniendo en cuenta tanto los imaginarios sociales asociados a

\footnotetext{
* Artículo de reflexión resultante de un proyecto de investigación estricta.

** Socióloga, Docente colombiana. Seis años de experiencia docente. Magíster por la Universidad Tecnológica de Bolívar. Especialista en Gerencia de Proyectos en la Universidad EAN. Correo electrónico: mcano@umayor.edu.co; ORCID: https://orcid.org/0000-0003-0138-7692
} 
cada uno, como la comprensión de los distintos factores sociales asociados a las representaciones de estos.

Palabras clave: champeta, cultura, identidad, imaginario social, picó, vallenato.

\title{
Social Imaginaries and Conflicts in the Expressions of Vallenato and Champeta Music in the Colombian Caribbean
}

\begin{abstract}
This reflection article, resulting from a strict research project, allowed to make an analysis of the discursive approach that frames the birth and development of champeta and vallenato music in the populations where they are representative (the cities Cartagena and Valledupar respectively) from a sociological perspective. In addition, it enabled to understand the existing relationship between the musical expressions of these genres, taking into account both the social imagery associated with each one, as well as, the understanding of the different social factors associated with their representations.
\end{abstract}

Keywords: champeta, culture, identity, music, social imaginary, picó, vallenato.

\section{Imaginários sociais e conflitos nas expressões da música Vallenata e Champeta no Caribe colombiano}

\section{Resumo}

Este artigo de reflexão, resultante de um estrito projeto de pesquisa, permitiu desde uma perspectiva sociológica uma análise da abordagem discursiva que enquadra o nascimento e o desenvolvimento de champeta e vallenato nas populações onde esses gêneros são representativos (as cidades de Cartagena e Valledupar respectivamente). Possibilitou 
compreender a relação entre as expressões musicais desses gêneros, levando em consideração tanto os imaginários sociais associados a cada um, quanto a compreensão dos diferentes fatores sociais associados às suas representações.

Palavras-chave: champeta, cultura, identidade, imaginário social, picó, vallenato.

\section{Introducción}

La cadencia de la música trasciende y envuelve todos los ámbitos en la vida del hombre. En este sentido, una de las representaciones a través de las cuales se puede explicitar esta relación dinámica entre dos estilos musicales que enmarcan las características de la vida caribeña, se encuentran con la música champeta ${ }^{1} y$ la vallenata ${ }^{2}$. Es fundamental en este análisis, la trascendencia, el grado de aceptación, evolución, recorrido histórico y la relación que han enmarcado dichos géneros musicales.

Para abordar esta relación se hace necesario establecer conceptualmente el término a través del cual se pretende revisar esta relación, esto es, precisar el horizonte significativo del concepto de imaginario social. Para ello, se hace necesario partir de la definición que al respecto realiza Castoriadis (1975) en tanto plantea la exigencia de la significación como universal y total, y en tanto postula su mundo de las significaciones como aquello que permite satisfacer esta exigencia (p. 312). De manera que toda sociedad,

\footnotetext{
${ }^{1}$ A lo largo y ancho del litoral caribe, se le da el nombre de champeta al cuchillo utilizado por la clase trabajadora campesina en los mercados públicos. A finales de 1960, se designó con este nombre a nueva expresión musical cuyos bailadores también usaban dicho cuchillo como arma en las riñas callejeras. En sus inicios, este tipo de música solo se escuchaba en los barrios populares de la ciudad y fue asimilada con mayor intensidad por la población de ascendencia africana radicada, inicialmente, en el barrio de Chambacú y, más tarde, reubicada en barrios periféricos de la ciudad (Martínez, 2011).

${ }^{2}$ El vallenato es un género musical autóctono de la Región Caribe de Colombia con su origen en la antigua provincia de Padilla (actuales sur de La Guajira, norte del Cesar y oriente del Magdalena) (BBC Mundo, 2015).
} 
para existir, necesita "su mundo" de significaciones. En este sentido, solo es posible pensar una sociedad bajo la particularidad que la enmarca. El concepto de "imaginario" destaca la dimensión de indeterminación última de toda significación a fin de dejar un espacio a la creatividad social en pleno. Desde esta perspectiva, el mundo de significaciones imaginarias de una sociedad es instituido, es obra de la sociedad y fundado en lo imaginario. Una sociedad se instituye bajo un universo de significaciones. Con base en lo anterior, se puede pensar entonces que el imaginario social es el conjunto de significaciones que no tiene por objeto representar "otra cosa”, sino un conjunto de esquemas organizadores que son condición de representatividad de todo lo que en una sociedad puede darse.

Este artículo de reflexión es producto de un proyecto de investigación estricta desarrollado al interior de la Corporación Universitaria Rafael Núñez, el proyecto llevó por nombre: "Cultura e identidad: imaginarios sociales y conflictos en las expresiones de la música vallenata y champeta”. Se desarrolló una investigación de tipo cualitativa, con enfoque etnográfico. El tema central de investigación fueron los imaginarios sociales y diversas expresiones y conflictos asociados a los géneros musicales en mención. Entre la población abordada, se encuentran diversos cantautores populares de vallenato y champeta, quienes fueron entrevistados con el objetivo de comprender las circunstancias que determinan el nacimiento, surgimiento y desarrollo de imaginarios sociales con respecto a dichas expresiones musicales en el contexto del Caribe colombiano.

\section{Relación en cuanto al origen y surgimiento de la champeta y el vallenato}

En primera instancia, y como hecho que permite relacionarlos, se observa que el origen de estos géneros musicales se presenta en contextos que 
denotan descrédito y poca aceptación por parte de la población en la cual surgieron y se desarrollaron inicialmente. El vallenato se remonta a la zona que hoy ocupan los departamentos del Cesar, Guajira y Magdalena; mientras la champeta surge en la ciudad de Cartagena de Indias y sus alrededores.

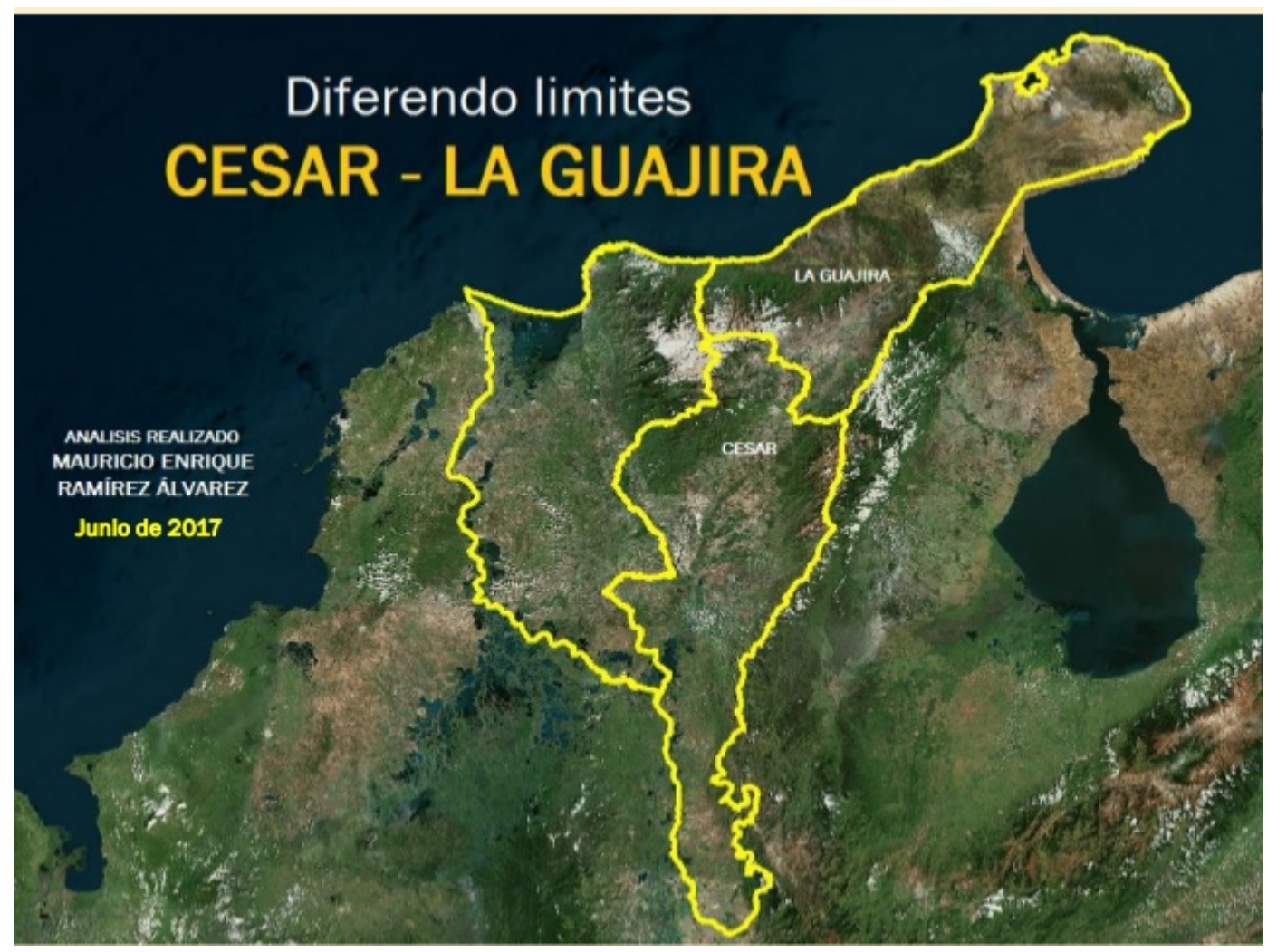

Figura 1. Departamentos de Cesar, Guajira y Magdalena.

Fuente: Diferendo Departamentos Cesar y La Guajira, Colombia (Ramírez, 2017). 


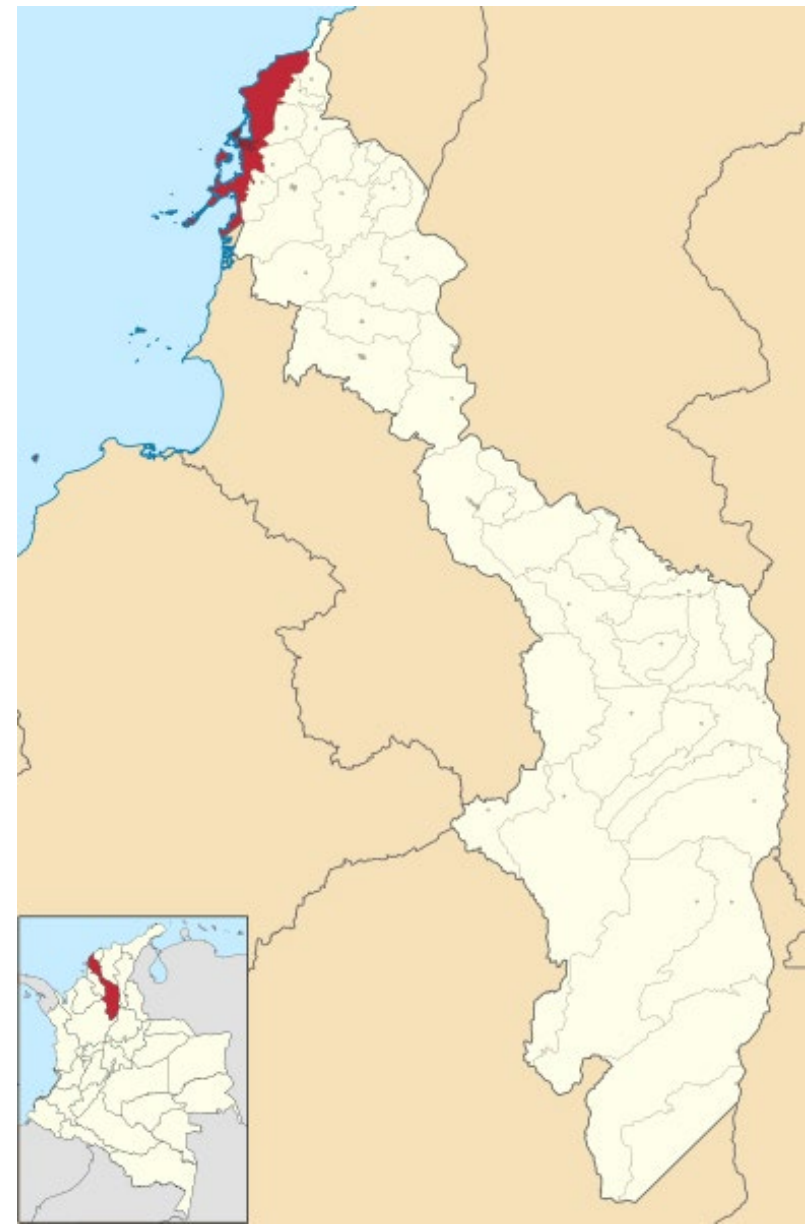

Figura 2. Visualización en color rojo de la ciudad de Cartagena de Indias.

Fuente: Milenioscuro (s. f.) ${ }^{3}$.

Estos géneros musicales tuvieron su génesis en medio de la discriminación y segregación social. Por un lado, el vallenato ha sido relacionado con parrandas hasta el amanecer, alcohol y desocupación; los músicos que se dedicaban a este oficio no eran bien vistos en las regiones. El investigador musical Julio Cesar Oñate Martínez, en su libro Héroes ocultos del vallenato (2013) señala: “Corrija a su hijo y no lo deje tocá esa vaina o va a quedá como Saúl, el flojo del pueblo; era la advertencia que don Pascual

\footnotetext{
${ }^{3}$ Este en un archivo de Wikimedia Commons, un depósito de contenido libre hospedado por la fundación Wikimedia.
}

\section{Análisis}

ISSN: 0120-8454 | e-ISSN: 2145-9169 | DOI: https://doi.org/10.15332/21459169

Vol. 53 N.o 99 | julio-diciembre de 2021 
Castro le hacía a Juan Granados, no hay hombre más flojo que un acordeonero" (p. 13).

Así mismo, en la obra Cien años de soledad (2007) de Gabriel García

Márquez, se puede evidenciar el siguiente fragmento:

Pasaba las tardes en el patio, aprendiendo a tocar de oídas el acordeón, contra las protestas de Úrsula que en aquel tiempo había prohibido la música en la casa a causa de los lutos, y que además menospreciaba el acordeón como un instrumento propio de los vagabundos herederos de Francisco el Hombre. (p. 139)

Teniendo en cuenta lo anterior, Urbina Joiro en su texto Lírica vallenata (2003), lo resalta al expresar que:

Hay suficiente evidencia para entender que lo que hoy se conoce como vallenato no nació hace cincuenta años o cien años. Más bien se palpa como un agitado proceso de siglos donde finalmente encajó mucho de la cultura amerindia, negroide y caucásica, amalgama que aún no se detiene. iCuánta reacción debió suscitar el reemplazo de las flautas de caña por el acordeón a fines del siglo XIX! Muchas fueron las innovaciones polémicas a lo largo del siglo XX: ¿Quién no oyó alguna de las reacciones que motivó ese paseo -romántico- brotado en 1963? (p. 12)

Por su parte, la Champeta también ha sido víctima del rechazo social por parte de los habitantes en la ciudad de Cartagena. Dicha marginalización incluso ha sido más representativa que la presentada en el vallenato. Este género connota desprecio y marginación desde su mismo nombre. La champeta es definida por el diccionario afrocolombiano como un cuchillo largo y ancho, que ha sido usado para designar en forma peyorativa a los 
residentes de barrios populares - champetúos-4 que escuchaban y bailaban la música africana y caribeña. Esta denominación luego fue adoptada por todo ese movimiento cultural que refleja las vivencias de una clase que por siglos ha sido negada y que quiere ser reconocida en su alteridad (Abril y Soto, 2004, p. 13).

Como puede observarse, la champeta no ha sido ajena a escenarios de segregación y exclusión por considerarse un género que denota marginalidad y violencia. Franklin y Del Río (2001) argumentan que:

[...] la champeta nació de la terapia criolla, imaginario de una cultura y una estética de los barrios marginados que se desarrollan en la parte sur de la Cartagena colonial, habitados por la porción poblacional desplazada de las zonas de conflicto, y de la misma ciudad de barrios como el antiguo Chambacú, Pueblo Nuevo, Pekín, Boquetillo y Getsemaní. Como producto de esa actitud de menosprecio a las zonas populares de la ciudad esta expresión cultural fue desconocida por los habitantes de las clases privilegiadas de la ciudad, que no la aceptaron ni en su letra ni en la plasticidad del baile, por la misma actitud del no-reconocimiento a ese otro habitante de la ciudad y por ser considerada como una expresión violenta de lo popular.

En este orden de ideas, Giraldo y Vega (2014), establecen que:

La música champeta ha estado fuertemente discriminada y subvalorada desde las clases altas y medias del Caribe colombiano. El origen de la palabra champeta se asoció con lo criminal y la violencia, ya que remite a los jóvenes que asistían a K-z5, provistos con champetas o champetillas,

\footnotetext{
${ }^{4}$ Sin tenerse una fecha exacta, los investigadores socioculturales han determinado que desde antes de los años veinte se le ha llamado "Champetúo" a los habitantes de barrios alejados del centro de Cartagena, asociados a los estratos más pobres y de características afrodescendientes. Este apelativo fue puesto por la élite económica en un intento de menospreciar a esta cultura sobreviviente. Este nombre, antiguamente aceptado y trasformado, se originó por la relación de la mencionada población con la machetilla "champeta", y se le asocia a elementos de vulgaridad, pobreza y negritud. (Parra, 2015)

${ }^{5}$ La caseta la cual se esgrime en la iconografía barrial como K-z, son aquellos lugares donde se desarrollan Las fiestas populares del contexto urbano del Caribe colombiano, se desarrolla en
}

\section{Análisis}

ISSN: 0120-8454 | e-ISSN: 2145-9169 | DOI: https://doi.org/10.15332/21459169

Vol. 53 N.o 99 | julio-diciembre de 2021 
propiciando peleas y agrediéndose con esta arma blanca mediana, utilizada principalmente en las plazas de mercado de Cartagena o en los contextos rurales del departamento de Bolívar. (p. 130)

Lo curioso de toda esta situación radica en que estas connotaciones y calificativos despectivos hacia la champeta en la ciudad de Cartagena, en especial hacia las personas que comparten dicho gusto musical -los denominados champetúos-, persisten en la actualidad, es común entre los habitantes situaciones asociadas a la exclusión y marginación social; de acuerdo con Giraldo y Vega (2014), la presencia de lo negro en las representaciones de la ciudad de Cartagena entra en un discurso que objetiviza la champeta a partir de las connotaciones discriminatorias y minusvaloraciones raciales que les confieren a los afrodescendientes, los cuales se encuentran en los barrios más pobres de la ciudad.

\section{Imaginarios sociales asociados a las expresiones musicales: vallenato y champeta}

\section{Empecemos por el vallenato}

En el imaginario social de las personas caribeñas podría creerse, en parte por la amplia aceptación de la que goza la música vallenata hoy en día a nivel nacional e internacional, que su transcendencia fue sencilla y abiertamente reconocida. Sin embargo, este género fue prohibido en uno de los clubes más emblemáticos de la ciudad, "EL Club Valledupar”, el cual todavía presta sus servicios. Así decía textualmente el artículo 62 de los estatutos del célebre lugar a finales de los años cincuenta y que cita Consuelo Araujo Noguera en una conferencia dictada en 1989 en el III Foro sobre el folclor vallenato, "Queda terminantemente prohibido llevar a

\footnotetext{
parqueaderos, solares o canchas de fútbol. La K-z tiende asociarse con las fiestas populares dentro de sus propias diferencias contextuales de acuerdo con la ciudad o los espacios urbanos que se describan (Sanz, 2011).
} 
los salones del Club Valledupar, música de acordeón, guitarra o parrandas parecidas, etc." (Araujo, 1989).

Sin duda alguna, uno de los procesos más importantes e influyentes en el impulso de la música vallenata fue la creación del Festival de la Leyenda Vallenata. El vallenato como baluarte del acervo cultural y musical Cesarense representa uno de los géneros con mayor trascendencia en el país y ha sido capaz de soportar la fuerza de la comercialización sin dejar de ser un auténtico representante y símbolo del folclor colombiano:

Hoy por hoy la música vallenata y particularmente el Festival de la Leyenda Vallenata la gran fiesta de la cultura popular fundada en 1968 y celebrada en Valledupar, la capital del departamento ha sido declarada por el Congreso de la República de Colombia como Patrimonio Cultural Nacional. (Visión de Desarrollo Territorial Departamental, 2011, p. 372)

De la música vallenata, puede decirse que pasó de escucharse en espacios que eran completamente restringidos a ser ampliamente aceptada en la actualidad, no solo en la ciudad de Valledupar y sus alrededores, sino también a nivel nacional e internacional:

El vallenato tradicional se ha ganado un lugar en el corazón de Colombia y el mundo, a tal punto, de ser declarado Patrimonio Inmaterial de la Humanidad por la Organización de las Naciones Unidas para la Educación, la Ciencia y la Cultura -Unesco, en el 2015. Anualmente, se realiza el Festival de la Leyenda Vallenata, celebración que convoca a propios y visitantes a exaltar esta música en Valledupar, capital mundial del vallenato. (Observatorio socioeconómico Cámara de comercio de Valledupar, 2018, p. 2)

Cabe resaltar que, el surgimiento del Festival Vallenato estuvo liderado por personajes representativos e influyentes de la región, entre ellos, folcloristas, investigadores musicales y políticos; el gobernador del Cesar 
de ese entonces, Alfonso López Michelsen, apoyó fuertemente esta iniciativa; el Nobel de literatura Gabriel García Márquez afirmó que: "Su Obra Cien Años de Soledad, es un vallenato de 350 páginas" (Rincón, 2017); estos representantes con el nacimiento de este evento, no solo consiguieron conservar y preservar esta tradición, sino que también lograron proyectarla a nivel nacional e internacional.

Tan proyectada está la música vallenata que, cada mes de abril que se lleva a cabo esta celebración, son recibidos en la ciudad de Valledupar alrededor de 145000 personas de diversos lugares del país; pero también es común ver en el marco de este evento visitantes de países como México, Venezuela, Estados Unidos, Panamá, Aruba, entre otros

Según el Observatorio socioeconómico de la Cámara de comercio de Valledupar (2018) los reportes de visitantes del terminal de transportes, del aeropuerto Alfonso López y la policía de tránsito y transporte, evidencian que alrededor de 145000 personas ingresaron a la ciudad de Valledupar en la semana del festival, principalmente, los viernes y sábados.

Como se puede observar, la aceptación hacia este género musical fue un proceso paulatino y sistemático, donde la influencia de personajes representativos en la vida política y folclore nacional fue determinante. Por ende, es de esperarse que los imaginarios sociales con respecto a esta música hoy en día sean mayoritariamente positivos - como se analizará posteriormente-, contrario a los imaginarios asociados a su origen y surgimiento donde las perspectivas se tornaban un tanto negativas para el desarrollo del género.

Bajo el enfoque anterior se observa cómo en la ciudad de Valledupar, contrario a lo que las personas foráneas se imaginan, no hay un acordeón ni una parranda vallenata en cada esquina, a menos que sea en el marco de 
la celebración del Festival de la Leyenda Vallenata. En una conversación desarrollada en el trabajo de campo con una entrevistada, ella expresó: “[...] yo pensaba que aquí se escuchaba más vallenato, que había una parranda vallenata en cada esquina, no vi ningún acordeón este fin de semana” (K. Barrios, comunicación personal, 3 de marzo, 2018).

Dicha entrevistada visitó la ciudad de Valledupar y recorrió alrededor de siete establecimientos, porque quería escuchar vallenato. Se imaginaba que la única música que se escuchaba en la ciudad era esa, textualmente expresó: “[...] vea usted, más vallenato escucho en Cartagena” (K. Barrios, comunicación personal, 3 de marzo, 2018). Notablemente se observa que, en la ciudad de Cartagena de Indias se pueden encontrar al menos seis establecimientos donde se escucha exclusivamente música vallenata; dos de los más representativos son Mi Maye y la Tertulia vallenata, a diferencia de Valledupar donde escasamente se identifica un solo establecimiento donde exclusivamente se escucha vallenato, que es Tierra de cantores. El hecho de ser nacidos en el departamento del Cesar no es directamente proporcional a saber cantar vallenato y, menos, saber tocar un acordeón; es una de las propuestas más frecuentes que se generan cuando una persona expresa ser oriundo de Valledupar: "¿ah eres de Valledupar? cántate una canción ahí, tócate un vallenato”. (S. Terán, comunicación personal, 12 de junio, 2017). Resulta contradictorio que, en no pocas ocasiones, personas que no son del Caribe logran conocer más las canciones vallenatas que alguien de Valledupar.

No todas las personas vallenatas tienen relación directa con los cantantes, compositores, acordeoneros, verseadores ${ }^{6}$ y demás músicos vallenatos; es

\footnotetext{
${ }^{6}$ Los verseadores vallenatos son aquellos participantes del concurso de piquería en el marco del Festival de la Leyenda Vallenata, cantan en cuartetas y en redondillas (que en el folclor le llaman versos de cuatro palabras) y en décimas (versos de diez palabras). La piquería es emoción, ingenio, manifestación de talento creativo. Es destreza mental y armónica para improvisar versos. (Atuesta, 2017).
} 
difícil encontrarlos en una calle de Valledupar o de compras en un establecimiento - como comúnmente se cree en el imaginario de los foráneos-. Esto, teniendo en cuenta que muchos cantantes no viven en la ciudad, muchos han emigrado a Barranquilla, Bogotá e incluso algunos se han radicado fuera del país. Allí se observan a los cantantes vallenatos de la misma forma en que los ven los visitantes, en una tarima cuando brindan una presentación, un concierto y en redes sociales.

Del mismo modo, no pocas veces, cuando se conoce que una persona es de Valledupar, automáticamente su casa se convierte en hospedaje. En conversación con un entrevistado, este expresó: “[...] es común escuchar expresiones como: 'Ay eres del Valle, ya tengo quien me invite al festival, ya tengo casa en abril, ya tengo donde bajar en festival'. (S. Castro, comunicación personal, 12 de enero 2018). No obstante, esta situación no siempre se convierte en un obstáculo o inconveniente, es precisamente esa abierta aceptación y difusión de esta fiesta, lo que provoca que cada día más personas quieran conocerla.

\section{Mientras tanto en la champeta}

Con respecto a la champeta, la suerte no ha sido distinta. De hecho, con la investigación realizada se pudo constatar que los imaginarios asociados a este género desde su inicio, desarrollo y etapa actual han sido despectivos en mayor medida en relación con los imaginarios asociados al vallenato.

Esta connotación negativa ha permeado muchos espacios sociales entre los cartageneros. En la década del 2000 en la ciudad se expide el Decreto 0109 del 2000 prohibiendo el uso de picós 7 por cuatro meses, asociando la

\footnotetext{
${ }^{7}$ Estos son sistemas de sonido ambulantes o escaparates descomunales que cuentan con consolas y grandes amplificadores que activan a los cartageneros de los barrios populares. Desde la década de 1940 existen estas máquinas, pero en 1960 fue que se consolidaron como elementos representativos de la cultura champetuda. Actualmente, los picós son íconos de la ciudad por ser los principales promotores de la música champeta (Estrada, 2016).
} 
champeta con violencia "El exalcalde de Cartagena Carlos Díaz Redondo, mediante decreto prohibió la música Champeta, argumentando que esta música era indecente y que sus seguidores eran violentos" (Lemaitre, 1999).

Esta determinación fue tomada después de que el exalcalde analizara la ola de violencia en la zona periférica de la ciudad, y sin un estudio riguroso o con argumentos sólidos, determinó que los bailes con picós eran los causantes del gran número de riñas presentadas los fines de semana en dichos festejos. Esta no ha sido la única prohibición asociada a la música champeta en la ciudad. En el año 2012, la ciudad vivió una circunstancia parecida:

El alcalde Mayor de Cartagena prohibió por dos meses los bailes con picó como medida para restablecer y conservar el orden público en la ciudad de Cartagena. La determinación, contemplada en el Decreto 0606 de 8 de mayo de 2012, se adoptó a raíz de los últimos incidentes en los barrios Nelson Mandela, Chiquinquirá y La Esperanza, en donde se celebraban bailes con estos aparatos de sonido y se registraron varias peleas. (El Universal, 2012)

Como puede observarse, los estereotipos y estigmatizaciones asociados a la champeta han transcendido las esferas de los entes gubernamentales, llegando al punto de expedir decretos en busca del restablecimiento del orden público; orden que, por algunos supuestos un tanto elitistas, ha sido alterado por acciones relacionadas con la champeta. A propósito, surge un gran interrogante asociado a estas medidas un tanto paradójicas respecto de la conservación del orden en la ciudad, “¿Quiénes son los violentos, la música o la gente?, La música y los picós no son violentos, violenta es la gente; tienen comportamiento violento, estén escuchando champeta o a Julio Iglesias" (M. Trespalacios, comunicación personal, 15 de octubre 2018). 
Para Charles King, uno de los principales exponentes de este género musical, el problema puede expresarse de la siguiente manera:

Una de las cosas más difíciles que ha tenido que enfrentar en su carrera musical es la estigmatización social. La razón es que a los llamados "champetúos" se les relaciona con las bajas esferas de Cartagena, es decir, se cree que son personas mal educadas, cuestionables y que tienen relación con la delincuencia. Por cuestiones de rechazo es que muy pocas mujeres han incursionado en la champeta. (El Universal, 2019)

Uno de los pioneros de la champeta en Cartagena de Indias, el artista Rafael Chávez, más conocido como "Kussima” y su guitarrista Ludwing Watts señalan que este rechazo puede estar incitado por la misma actitud apática de los propios cartageneros, anotan que la misma ciudadanía es la que se ha encargado de generarle falsos estereotipos al género. Para ellos, los forasteros no tienen el ideal de que la champeta es "violenta", como generalmente se le conoce, esta actitud se asume porque se escucha eso de los mismos habitantes de la ciudad: "Para nosotros la champeta es un estilo de vida, es nuestra representación cultural, lamentablemente hoy el termino champetúo se confunde con ser guache, malandro y plebe, ese es el imaginario arraigado en la población" (R. Chávez, comunicación personal, 13 de mayo, 2017).

Según estos artistas:

El origen de la música champeta tenía como objetivo, establecerla como ritmo único y autóctono de la ciudad, lamentablemente no resultó como queríamos y ha sido la misma población quien le ha dado esa connotación de violenta, la champeta no es violenta, violenta es la gente, la champeta no genera problema, los que generan problemas son las personas. (L. Watts, comunicación personal, 13 de mayo, 2017) 
En este mismo sentido, Giraldo y Vega (2014) ponen de manifiesto que estas connotaciones negativas se reproducen constantemente, en donde la palabra verbena, $\mathrm{K}-\mathrm{z}$, picó y champeta son dispositivos de violencia y sanción. De esto se infiere que, en el imaginario urbano, la champeta reproduce los estigmas sociales, aunque no necesariamente son estigmas raciales como sí ocurre en Cartagena.

Por su parte, Elizabeth Cunin (2007) lo plantea de la siguiente manera:

La champeta cuando se inscribe en las relaciones sociales de Cartagena reproduce y exacerba la marginalización y la exclusión de lo "negro", características de la ciudad. La champeta nos muestra el proceso de designación racial de una cultura popular. Seguramente la champeta rompe con una serie de normas (sociales, artísticas, sonoras, etc.) implícitas en Cartagena e inspiradas del modelo de la élite de la ciudad. [...] La dimensión racial es, más bien, el resultado de una calificación exterior, que moviliza la categoría "negro" para justificar el rechazo de esta música. La designación racial de los champetúos parece responder sobre todo a una lógica de "etiquetaje" de la desviación más que a una voluntad deliberada de romper el evitamiento. (p. 7)

De hecho, las mismas canciones de champeta ponen de manifiesto la diferenciación respecto de la estratificación social, esa diferencia marcada en lo que puede significar ser o no champetúo. Muestra de esto es una canción de la agrupación Bazurto All Stars que tuvo mucho auge en la ciudad hace algunos años, la letra hace referencia a una chica de clase alta a la que le empieza a gustar la champeta, por esta razón recibe el denominativo de "Pupileta"; Pupi por pertenecer a la clase alta y coleta ${ }^{8}$ por su gusto compartido por la champeta. Aquí fragmentos de la letra de la canción:

\footnotetext{
${ }^{8}$ En la ciudad de Cartagena, coleta hace referencia a vándalo, villero. Persona que habita los barrios bajos o al menos lo parece (Diccionario de costeño, 2010).
} 
Ella bailaba reggaetón y era loca por David Guetta, le gustaba Daddy y el Don pero ahora baila champeta [...] ella ahora baila champeta, ella rompe en la discoteca, le dicen la pupileta, porque es pupi y coleta [...] se monta en su viaje, se pone bien coleta y en el barrio ahora le dicen la pupileta. (Bazurto All Stars, 2015)

Teniendo en cuenta lo anterior, puede verse arraigado en el imaginario de la población la imagen de que la champeta está relacionada con conceptos que van desde un mal vestir, violencia, drogadicción y vulgaridad. El estereotipo que se manifiesta y familiariza en una parte importante de la población, obedece, en gran medida, a la consolidación de pandillas en la estructura urbana que surge y fortalece entre las décadas de los años ochenta, época en que se posiciona la música africana, y en los años noventa, en donde se va proyectando la champeta.

Los actos de violencia que se desarrollaron entre pandillas en las denominadas K-z (casetas) reafirmaron los vínculos negativos sobre las músicas populares. Sumado a esto, también la actitud de los propios ciudadanos cartageneros quienes, en ocasiones, son los que propician la formación sistemática de dichos estereotipos en su mayoría negativos; así como, el poco apoyo e impulso de dicho género por los entes gubernamentales correspondientes.

\section{Conclusiones}

El vallenato y la champeta tienen gran incidencia y representación en el Caribe colombiano, particularmente en los territorios de Valledupar y Cartagena respectivamente, espacios centrales en el desarrollo de este estudio. Se pudo evidenciar en los resultados de investigación que ambos géneros se relacionan en algunos aspectos de las etapas de origen, evolución y desarrollo musical actual. 
En este orden de ideas, la primera relación que se observa es entre el concepto de imaginario social, abordado desde los postulados de Castoriadis (1975): "desde esta mirada se puede anotar que, cada sociedad crea su propio mundo de significaciones". En el vallenato y la champeta los imaginarios están asociados a los territorios mencionados (Valledupar y Cartagena) en cada momento de la historia. La relación existente connota la cultura e identidad de las poblaciones donde estos son representativos; de esta forma, se generan unos imaginarios completamente negativos al origen y surgimiento de ambos géneros. Sin embargo, en cuanto a la evolución y desarrollo musical actual respecto del vallenato, los imaginarios asociados tienden a ser positivos, mientras que, por los lados de la champeta, se tornan negativos.

El origen y surgimiento de estos estilos musicales, como se mencionó anteriormente, estuvo asociado a estereotipos negativos y un tanto despectivos. Respecto al vallenato, en sus inicios, estuvo asociado a acciones relacionadas con la vagancia, flojera y juerga, tal como lo manifiestan autores como Oñate (2013) "No hay hombre más flojo que un acordeonero" (p. 13). En relación con la champeta, la situación no fue diferente. El asociativo a estigmas negativos también fue muy frecuente. En el proceso evolutivo de dichos géneros, se han presentado una serie de sucesos y circunstancias que han favorecido su desarrollo y evolución. Sin embargo, los estereotipos positivos siguen favoreciendo a la música vallenata; parte de esa aceptación puede deberse a la declaración que hizo la Unesco hacia el año 2015 del vallenato tradicional como "Patrimonio Inmaterial de la Humanidad", lo que sin duda ha generado una incidencia positiva en el género.

En la champeta las circunstancias han sido distintas y un poco adversas comparadas con las del vallenato. La ciudad de Cartagena, en más de una ocasión, ha sido protagonista de decretos en los cuales se prohíben los 
bailes con picós de champeta como medida de prevención de desmanes y disturbios asociados a los festejos con dicha música; uno de ellos fue el Decreto 0109 del 2000 expedido por el exalcalde de Cartagena Carlos Díaz Redondo, "argumentando que esta música era indecente y que sus seguidores eran violentos" (Lemaitre, 1999).

De igual forma, se entiende que este rechazo puede estar influenciado por los mismos cartageneros. Es posible que sean ellos mismos los protagonistas y creadores de esta serie de estigmas negativos:

Los foráneos no conocen acerca de la champeta, mucho menos la asocian con "violencia"; esta actitud se asume porque generalmente se escucha de los mismos habitantes de la ciudad, lamentablemente hoy el termino champetúo se confunde con ser guache, malandro y plebe, ese es el imaginario arraigado en la población. (R. Chávez, comunicación personal, 13 de mayo, 2017)

Indiscutiblemente, los imaginarios sociales inmersos en los territorios asociados a estos géneros musicales, como lo son las ciudades de Valledupar y Cartagena -epicentros de este estudio-, no se desprenden únicamente del trasegar y evolución de estos estilos propiamente musicales. Se pudo observar a través de la investigación que también interfieren factores históricos, familiares, socioeconómicos e incluso, con mucha incidencia, factores políticos. Estos factores, de una u otra manera, determinan todo tipo de estigmas, estereotipos y paradigmas bien sea positivos o negativos asociados, tanto al género musical, como a las personas y territorios que se relacionan con ellos.

\section{Referencias}

Abril, C. y Soto, M. (2004). Entre la champeta y la pared. El futuro económico y cultural de la industria discográfica de Cartagena. Observatorio del Caribe Colombiano, Convenio Andrés Bello. http://openbiblio.flacsoandes.edu.ec/libros/143186-opac 
Alcaldía de Cartagena. (2000). Decreto 0109. El cual prohibió el uso del picós en la ciudad de Cartagena por cuatro meses.

Alcaldía de Cartagena. (mayo 8, 2012). Decreto 0606. El cual fue expedido y firmado por el Ex - alcalde Campo Elías Terán (QEPD), como medida para restablecer y conservar el orden público en la ciudad de Cartagena.

Atuesta, J. (2017). Claves en la piqueria vallenata. El pilón.

Bazurto All Stars. (2015). La pupileta [canción]. Bazurto Records.

$B B C$ Mundo. (2015). 13 vallenatos esenciales que hay que conocer ahora que es patrimonio de la humanidad. Redacción BBC.

https://www.bbc.com/mundo/noticias/2015/12/151201_colombia_13_vallenatos _escenciales_nc.

Cámara de comercio de Valledupar. (2018). Balance comercial y turístico. $51^{\circ}$ versión festival de la leyenda vallenata. Observatorio socioeconómico Cámara de comercio de Valledupar.

Castoriadis, C. (1975). La institución imaginaria de la Sociedad. Tusquets Editores.

Cunin, E. (2006). De Kinshasa a Cartagena, pasando por París: itinerarios de una "música negra", la champeta. Aguaita, (15-16), 176-192.

El Universal. (mayo 9, 2012). Listo decreto que prohíbe bailes con picó. https://www.eluniversal.com.co/regional/listo-decreto-que-prohibe-bailes-conpico-75799-OUEU158754

El Universal. (julio 22, 2019). El regreso de Charles King, 'El cronista de la champeta'. https://www.eluniversal.com.co/regional/listo-decreto-que-prohibe-bailes-conpico-75799-OUEU158754.

Estrada, S. (junio 1 de 2016). Los picós íconos musicales de la champeta en Cartagena. El Universal. https://www.eluniversal.com.co/cultural/los-picos-iconos-musicalesde-la-champeta-en-cartagena-227064-EQEU332897

Franklin, P. y Del Río, J. (2001). Terapia criolla, elogio a la ilegalidad. Revista Noventa y Nueve de Investigación Cultural, (2).

García Márquez, G. (2007). Cien años de soledad. Edición Conmemorativa, Real Academia Española, Asociación de Academias de la Lengua Española. 
Giraldo Barbosa, J. E. y Vega Casanova, J. (2014). Entre champeta y sonidos africanos: fronteras difusas y discusiones sobre "músicas negras" en el Caribe Colombiano. Memorias: Revista Digital de Historia y Arqueología desde el Caribe, (23), 128-152.

Lemaitre, E. (noviembre 21, 1999) La ciudad barrilete, Cartagena. El Universal. Dominical, no 715 .

Martínez, l. (2011). La champeta: una forma de resistencia palenquera a las dinámicas de exclusión de las elites "blancas" de Cartagena y Barranquilla entre 1960 y 2000. Boletín de Antropología Universidad de Antioquia, 25(42).

Oñate Martínez, J. C. (2013). Héroes ocultos del vallenato. Maremágnum Editorial.

Parra, A. (julio 10, 2015). Tu vida al ritmo champeta. Tú vida bailando al ritmo champeta. http://tuvidabailandoalritmochampeta.blogspot.com/2015/

Ramírez, M. (2017). Diferendo Departamentos Cesar y La Guajira, Colombia. Slideshare. https://es.slideshare.net/MauricioEnriqueRamirez/diferendo-dpatoscesar-y-la-guajira

Rincón, J. (31 de mayo de 2017). Cien años de soledad, el vallenato más largo de la historia. El pilón. https://elpilon.com.co/cien-anos-soledad-vallenato-mas-largola-historia/.

Sanz, M. A. (2011). Fiesta de picó. Champeta, espacio y cuerpo en Cartagena, Colombia. [Tesis de pregrado, Universidad del Rosario]. Repositorio Universidad del Rosario. https://repository.urosario.edu.co/bitstream/handle/10336/260o/SanzGiraldoMariaAlejandra-2011.pdf

Urbina Joiro, H. (2003). Lírica vallenata. Convenio Andrés Bello.

Visión de Desarrollo Territorial Departamental. (2011). Cesar Caribe 2032: Un departamento en crecimiento generando bienestar. Departamento Nacional de planeación. Gobernación del Cesar. 